\title{
Assessing Survival and Grading the Severity of Complications in Octogenarians Undergoing Pulmonary Lobectomy
}

\author{
Andrew Feczko, ${ }^{1}$ Elizabeth McKeown, ${ }^{2}$ Jennifer L. Wilson, ${ }^{3}$ Brian E. Louie, ${ }^{1}$ \\ Ralph W. Aye, ${ }^{1}$ Jed A. Gorden, ${ }^{1}$ Eric Vallières, ${ }^{1}$ and Alexander S. Farivar ${ }^{1}$ \\ ${ }^{1}$ Division of Thoracic and Foregut Surgery, Swedish Medical Center and Cancer Institute, 1101 Madison Street, \\ Suite 900, Seattle, WA 98104, USA \\ ${ }^{2}$ Surgical Specialists of Charlotte, 2001 Vail Ave., Suite 320, Charlotte, NC 28207, USA \\ ${ }^{3}$ Department of Surgery, Chest Disease Center, Beth Israel Deaconess Medical Center, 185 Pilgrim Road, Suite 201, \\ Boston, MA 02215, USA \\ Correspondence should be addressed to Andrew Feczko; andrew.feczko@swedish.org
}

Received 15 November 2016; Revised 9 January 2017; Accepted 11 January 2017; Published 8 February 2017

Academic Editor: Hisao Imai

Copyright (C) 2017 Andrew Feczko et al. This is an open access article distributed under the Creative Commons Attribution License, which permits unrestricted use, distribution, and reproduction in any medium, provided the original work is properly cited.

Introduction. Octogenarians are at increased risk for complications after lung resection. With alternatives such as radiation, understanding the risks of surgery and associated survival are valuable. Data grading the severity of complications and longterm survival in this population is lacking. We reviewed our experience with lobectomy in octogenarians, grading complications using a validated thoracic morbidity and mortality schema. Methods. We retrospectively reviewed consecutive patients aged $\geq 80$ undergoing lobectomy between 2004 and 2012. Demographics, clinical/pathologic stage, complications, recurrence, and mortality were collected. Complications were graded by the Seely thoracic morbidity and mortality model. Results. 45 patients (mean age 82.2 years) were analyzed. The majority of patients $(28 / 45,62 \%)$ were clinical stage IA/IB. $62 \%(28 / 45)$ of patients experienced a complication. Only $15.6 \%$ (7/45) were considered significantly morbid ( $\geq$ grade IIIB) per the Seely model. Perioperative mortality was $2 \%$ and half of patients were living at a follow-up of 53 months. Overall five-year survival was $52 \%$. Conclusions. In carefully selected octogenarians, lobectomy carries a $15.6 \%$ rate of significantly morbid complications with encouraging overall survival. These data provide the basis for a more complete discussion with patients regarding lobectomy for lung cancer.

\section{Introduction}

Due to the high incidence of lung cancer in octogenarians, surgeons are increasingly confronted with the clinical challenge of how best to treat these patients with resectable lung cancer. Fourteen percent of patients diagnosed with lung cancer in the United States from 1988-2003 were $\geq 80$ years old [1] with the peak incidence occurring between ages 75-79 [2]. With the general population living longer and the baby boomer generation reaching this age bracket in the next decade, it is imperative that we better understand complications and survival in this growing age group.

Making optimal treatment recommendations can be challenging for treating physicians as octogenarians in general have more comorbidities and a worse performance status than the younger population. While the gold standard surgical therapy for early stage lung cancer remains anatomic resection [3], physicians may be hesitant to refer these patients for surgical evaluation and other treatment options including stereotactic body radiation therapy (SBRT) and wedge resection may be suggested [4]. Currently, long-term survival data for SBRT are limited and show a wide range of survival ranging from a 3-year survival of $42 \%$ for stage I [5] to $83 \%$ for stage IA [6] (see Table 4). In addition, the surgical literature regarding octogenarians with lung cancer is diverse and often includes patients with a wide variety of clinical stages and resections (i.e., wedge, lobectomy, and pneumonectomy). As a result, broad 5-year survival rates ranging from $18.2 \%$ to $69.6 \%$ [7-17] have been reported which are likely strongly related to variable inclusion data and extent of resection (see Table 3). 
Prior publications have documented that octogenarians experience higher complication rates after lung resection which ranges from 8.4 to $68.8 \%$ [7-14, 16-19]. Data regarding the severity, morbidity, or impact of those complications has yet to be elucidated using a standardized validated system, leaving physicians with an incomplete understanding of assessing short-term surgical risks versus long-term benefit. Furthermore, surgeons lack the data that allow them to characterize morbidity and complications beyond "major or minor" when counseling their patients. In order to reconcile this, the Seely morbidity and mortality schema was designed for application to thoracic surgical patients [20]. It provides a standardized and validated framework for physicians to describe complications based on the level of intervention required [20].

Defining complication severity is important in the overeighty population to allow for accurate patient counseling regarding surgical outcomes and to guide surgical treatment algorithms. We sought to gain further understanding of the inherent morbidity assumed by an octogenarian deemed appropriate for lobectomy and to characterize complications based on a validated thoracic surgery schema. Furthermore, we assessed long-term survival to contextualize more completely short-term risks versus long-term survival.

\section{Methods}

We performed a single center retrospective review of consecutive patients aged eighty or greater who underwent lobectomy approached by thoracotomy, video assisted thoracoscopic surgery (VATS), or robotic assisted methods between 2004 and 2012. All patients were staged according to the American Joint Committee on Cancer (AJCC) 7th edition guidelines [21]. The Institutional Review Board (IRB) approved the study and data was entered into a secure database. Individual patient consent was waived due to the retrospective nature of the study.

Key data elements included age, gender, body mass index (BMI), comorbidities, percent of predicted forced expiratory volume expired in 1 second (FEV1), percent of predicted diffusion capacity of carbon dioxide (DLCO), operative approach, conversion of minimally invasive operative approach to thoracotomy, mean operative time, mean estimated blood loss, intraoperative mortality, complications, intensive care unit (ICU) stay, clinical and pathologic stage, procedure performed, hospital length of stay (LOS), posthospital patient disposition to home or skilled nursing facility (SNF), follow-up duration, disease recurrence, patient status (living or deceased), and cause of death if applicable.

Patients were staged as follows. Cross sectional imaging was used to determine tumor size and clinical T stage (cT). Clinical node negative status ( $\mathrm{cN} 0$ ) was determined if the patient had a standardized uptake value (SUV) $<1.5$ on positron emission tomography (PET), a biopsy of a PET positive node that was ultimately pathologically benign, or biopsy of lymph node(s) $>1 \mathrm{~cm}$ in largest diameter that was pathologically benign.

Each attending surgeon determined patient operability based on the patient's preoperative imaging, medical comorbidities, activity tolerance, pulmonary function testing, and nutrition status. Specifically, this included patients with an ECOG score of 0 or 1, a FEV1 and DLCO > 40\% predicted after lobectomy, and no anginal symptoms. Patients with a significant cardiac history or questionable cardiac reserve were referred to their cardiologist or newly evaluated for clearance to tolerate a surgery and general anesthetic. Each patient performed an in-office stair walk where heart rate and oxygen saturation were recorded while walking at least two flights of stairs. Patients who became significantly dyspneic or had an oxygen saturation less than $92 \%$ while walking two flights were considered inoperable. No comorbidity precluded consideration for an operation; however, care was taken to optimize these conditions (i.e., blood glucose and pulmonary function) prior to consideration of surgery. This assessment determined the ability of a patient to tolerate general anesthetic and a lobectomy through any modality. Once operability was determined, the decision to proceed with a thoracotomy or minimally invasive (VATS or robotic) procedure was at the surgeon's discretion.

We employed the Seely classification system, which characterizes complication severity based on the need for general anesthesia separating minor from major complications. Grade I complications include any complication not requiring intervention; grade II complications include any complication requiring pharmacologic intervention; grade IIIA complications include any intervention not requiring general anesthesia. Major complications were defined as grade IIIB (any complication requiring general anesthesia), grade IV (any complication requiring ICU admission, single organ failure, or reintubation), and grade $\mathrm{V}$ (complications leading to death) (see Table 2).

Clinical follow-up was calculated from the date of discharge to the last clinic visit. In cases where a patient was lost to follow-up, status was verified by using the social security death registry and/or by contacting their primary care physician. Survival data was analyzed by the KaplanMeier method. A univariate analysis was performed to identify factors that influence overall survival including medical comorbidities, clinical and pathologic stages, tumor size, and complications (all and severe $\geq$ IIIB). Statistical analyses were completed using SPSS 18.

\section{Results}

A total of 45 (male $=23$ ) patients underwent lobectomy. No patients received neoadjuvant therapy prior to resection. The most common comorbidity was hypertension (56\%) (see Table 1). All patients were high functioning with an ECOG of $0(39 / 45,86.7 \%)$ and $1(6 / 45,13.3 \%)$. The majority of patients $(42 / 45,93.3 \%)$ underwent preoperative cardiac evaluation by a cardiologist. Nearly all patients were clinically staged with a diagnostic chest CT and PET. Thirty-nine patients (86.7\%) underwent preoperative cervical mediastinoscopy. Clinical staging information was available for $41 / 45$ patients. Of these, 20 were stage IA (51\%), 8 stage IB (21\%), 5 stage IIA (11\%), 1 stage IIB (2.2\%), and 5 stage IIIA (11\%). Two patients underwent lobectomies for metastasectomy, and staging information was unavailable for the remaining 
TABle 1: Patient demographics.

\begin{tabular}{lc}
\hline Mean age (range) & $82.2(80-89)$ \\
Mean BMI (range) & $25(17-43)$ \\
Mean FEV1\% predicted (range) & $86(43-123)$ \\
Mean DLCO\% predicted (range) & $71(42-110)$ \\
Tobacco history: $n(\%)$ & $39(87 \%)$ \\
Mean pack years & 30 \\
Comorbidities: $n$ (\%) & \\
HTN & $25(56 \%)$ \\
CAD & $14(31 \%)$ \\
COPD & $12(27 \%)$ \\
Prior CT surgery & $12(27 \%)$ \\
Atrial fibrillation & $10(22 \%)$ \\
Diabetes & $3(7 \%)$ \\
Renal disease & $1(2 \%)$ \\
Steroid dependent & $1(2 \%)$ \\
\hline BMI: body mass index, FEVl: forced expiratory volume at one second, \\
DLCO: diffusing capacity for lung for carbon monoxide, HTN: hypertension, \\
CAD: coronary artery disease, CT: cardiothoracic, and COPD: chronic \\
obstructive pulmonary disease.
\end{tabular}

four patients. All patients undergoing lobectomy for lung cancer were clinically node negative and without evidence of metastasis ( $\mathrm{cN} 0$ and $\mathrm{cM} 0$ ) prior to resection.

Thoracotomy was performed most commonly (27/45, $60.0 \%)$ followed by VATS $(12 / 45,26.7 \%)$ and robotic assisted $(3 / 45,6.7 \%)$. In two cases $(2 / 15,13.3 \%)$, a minimally invasive approach was converted to thoracotomy. Mean operative time was 228 minutes (range 106-381 minutes) and mean estimated blood loss was $50 \mathrm{~mL}$. There was no intraoperative mortality. Disposition data was available for $32 / 45$ patients and $27 / 32(84.4 \%)$ were admitted to the ICU postoperatively. The average ICU LOS was 3 days (range 1-13).

The pathology for most patients was non-small-cell lung cancer (NSCLC) $(39 / 45,86.7 \%)$ and the majority of these were adenocarcinoma $(26 / 39,66.7 \%)$. Two patients had metastatic disease from an extrathoracic source (colorectal and uterine stromal cell carcinoma) and 2 patients had a spindle cell neoplasm (one bronchioloalveolar carcinoma and one neuroendocrine tumor). In keeping with the early clinical stage of this population, the most common pathologic stage in the NSCLC patients was IB $(13 / 39,33.3 \%)$. Ten patients $(10 / 39,25.6 \%)$ were IA; 3 patients were IIA $(3 / 39,7.7 \%)$; 3 patients were IIB (3/39, 7.7\%); 7 patients were IIIA (7/39, 18\%); 1 patient was IIIB $(1 / 39,2.6 \%)$, and 2 patients were Stage IV $(2 / 39,5.1 \%)$ on final pathology.

Minor complications (grades I-IIIA) occurred in 46.7\% (21/45) of patients. New onset atrial fibrillation requiring medical therapy was the most common complication $(22.2 \%$, $10 / 45)$. Ten patients $(22.2 \%)$ had a prolonged air leak or fluid collection that necessitated chest tube for $>5$ days. Nine of these air leaks resolved while the patient was in hospital, but 1 patient was discharged home with a chest tube due to a persistent leak. Four patients (8.9\%) were discharged from the hospital with supplemental oxygen therapy per nasal cannula.

Severe postoperative complications ( $\geq$ IIIB) occurred in $15.6 \%(7 / 45)$ of patients. Three patients (6.7\%) developed pneumonia requiring ICU care. Two patients (4.4\%) required return to the operating room for control of postoperative hemorrhage within twenty-four hours of the initial operation. Additional severe complications included myocardial infarction $(2 / 45,4.4 \%)$ and one inpatient sustained an ankle fracture due to a fall, which subsequently required operative fixation (see Table 2). Furthermore, 1 patient (2.2\%) with steroid-dependent COPD died in the perioperative period on postoperative day 13 due to sepsis induced multiple organ system failure.

Over half of the patients had a postoperative complication of some sort (28/45, 62\%). Additional complications not captured in the Seely classification system included unexpected transfers to the ICU for cardiac monitoring due to atrial fibrillation which occurred in 3/45 (6.7\%). Thirty-six of the 45 patients had disposition data available. Of these patients, $88.9 \%(32 / 36)$ were able to be discharged home and $11.1 \%$ (4/36) were discharged to a skilled nursing facility.

During the mean follow-up period of 53 months (range 1 week to 84 months), $13.3 \%$ (6/45) had disease recurrence at a mean of 25 months from their operation (4 months-84 months) and 51.1\% (23/45) died. Causes of death included lung cancer recurrence in $43.5 \%$ (10/23), multiorgan system failure in the perioperative period, stroke, amiodarone toxicity, and sepsis (1 each). Nine patients died of unknown causes. Mean 5-year overall survival calculated by the KaplanMeier method was 52\%. Medical comorbidities, clinical stage, tumor size, any complication (grades I-V), and severe complications ( $\geq \mathrm{IIB}$ ) did not significantly influence survival on univariate analysis.

\section{Discussion}

While anatomic lung resection remains the standard of care for the treatment of NSCLC [3], octogenarians are less likely to be offered a lobectomy than younger patients. A Surveillance, Epidemiology and End Results (SEER) database review of 45,912 of patients aged $\geq 80$ demonstrated that octogenarians were twice as likely to receive no local tumor specific therapy (radiation or surgery) when compared to younger patients despite a comparable rate of early stage cancers in both groups [1]. This was even significant when comparing octogenarians to patients aged $70-79$ ( $47 \%$ offered no radiation or surgery versus 28\%) [1]. Another study demonstrated the same trend and showed that as age increases, patients undergo anatomic resection less often than the general population and are offered radiation therapy more often than surgery [22] despite the fact that radiation therapy or nonanatomic lung resection remains second line therapy for patients with operable NSCLC [3].

Even with improvement in radiation methods from external beam radiation therapy, stereotactic body radiation (SBRT), or stereotactic ablative radiation therapy (SABR) [23], resection offers the best chance for local control [24]. In studies including octogenarians who are surgically or medically inoperable, treatment decisions are a bit easier for healthcare providers. This study sought to understand and clarify the risks and outcomes of the gold standard therapy (resection) within this group. 
TABLE 2: Complications categorized by the Seely thoracic morbidity and mortality classification system.

\begin{tabular}{|c|c|c|c|}
\hline Grade & $\begin{array}{c}\text { Patients } \\
n / 45(\%)^{*}\end{array}$ & Definition of complication & $\begin{array}{c}\text { Complication description } \\
(n / 48, \%)^{* *}\end{array}$ \\
\hline I & $2(4.4 \%)$ & $\begin{array}{l}\text { Complication that does not } \\
\text { require any intervention }\end{array}$ & $\begin{array}{c}\text { Asymptomatic vocal cord } \\
\text { paralysis }(1,2.1 \%) \text {, urinary } \\
\text { retention }(1,2.1 \%) \text {, ileus }(2 \text {, } \\
4.2 \%)\end{array}$ \\
\hline II & $10(22.2 \%)$ & $\begin{array}{c}\text { Pharmacologic therapy or } \\
\text { minor intervention } \\
\text { required }\end{array}$ & $\begin{array}{c}\text { Atrial fibrillation (14, } \\
29.2 \% \text {, with } 10 \text { being new } \\
\left.\text { onset; } 10 / 48,20.8 \%{ }^{* * *}\right), \\
\text { esophagitis }(2,4.2 \%) \text {, new } \\
\text { home } \mathrm{O}_{2}(4,8.3 \%) \text {, serious } \\
\text { electrolyte disturbance }(1, \\
2.1 \%) \text {, acute kidney injury } \\
(1,2.1 \%) \text {, chyle leak }(1,2.1 \%)\end{array}$ \\
\hline IIIA & $9(20 \%)$ & $\begin{array}{l}\text { Interventions not requiring } \\
\text { general anesthesia }\end{array}$ & $\begin{array}{c}\text { Home with chest tube }(1, \\
2.1 \%) \text { stroke }(1,2.1 \%), \\
\text { bleeding not requiring } \\
\text { transfusion }(1,2.1 \%), \\
\text { development of a PTX } \\
\text { requiring drainage }(1, \\
2.1 \%) \text {, chest tube duration }> \\
5 \text { days }(10,20.8 \%)\end{array}$ \\
\hline IIIB & $3(6.7 \%)$ & $\begin{array}{l}\text { Interventions requiring } \\
\text { general anesthesia }\end{array}$ & $\begin{array}{c}\text { Return to OR: } \\
\text { postoperative hemorrhage } \\
(2,4.2 \%) \text {, fracture fixation } \\
\text { after fall }(1,2.1 \%) \\
\end{array}$ \\
\hline IV & $3(6.7 \%)$ & $\begin{array}{l}\text { Complication requiring } \\
\text { ICU support, reintubation, } \\
\text { single or multisystem organ } \\
\text { failure }\end{array}$ & $\begin{array}{c}\text { MI }(2,4.2 \%), \text { pneumonia } \\
(4,8.3 \%), \text { respiratory } \\
\text { failure }(1,2.1 \%)\end{array}$ \\
\hline $\mathrm{V}$ & $1(2.2 \%)$ & $\begin{array}{l}\text { Any complication leading } \\
\text { to death }\end{array}$ & Multiorgan failure $(1,2.1 \%)$ \\
\hline
\end{tabular}

* Several patients had more than 1 complication and are listed in the category corresponding to the complication with the highest Seely grade.

${ }^{* *}$ Complications are listed individually in this column and many include multiple complications in the same patient(s).

**** The four patients with preexisting atrial fibrillation were not included in the complication rate.

$\mathrm{O}_{2}$ : oxygen, OR: operating room, and MI: myocardial infarction.

There has been a broad attempt across the surgical literature to classify complications by severity in order to standardize complication reporting. The National Cancer Institute Common Terminology Criteria for Adverse Events (CTCAE) is a system which grades adverse events across multiple diverse areas of medical care on a 1-5 scale [25]. The validated Clavien-Dindo complication classification scheme was created for application to general surgery patients and is graded based upon the level of intervention required to treat the complication, a more practical system than simply separating events into major and minor categories [19]. Seely et al. published a validated extension of the ClavienDindo system for application to the thoracic surgery patient population [20]. Like the CTCAE, complications are graded from I to $\mathrm{V}$ based on the level of intervention required to treat the complication, with minor complications considered grades I-II and major complications that result in significant morbidity listed as grades III-V [20]. We used Seely grade in order to provide us with a specific understanding of the practical morbidity faced by octogenarian population when undergoing lung resection.
Lower \% predicted FEV1 [19], thoracotomy as approach $[9,19]$, resection greater than wedge $[19,26]$, and mediastinal lymph node dissection $[11,16]$ are associated with higher complication rates in octogenarians undergoing lung resection. In addition, Port et al. demonstrated a statistically significant shorter length of stay and less ICU admission rates with VATS over thoracotomy in octogenarians undergoing lobectomy [9]. While we did not seek to find differences in operative approach in this study, we did not observe a difference in complication rates between thoracotomy, VATS, and robotic, likely due to the study size. Minimally invasive approaches to lung resection have been shown to be associated with fewer complications by many authors $[9,19]$ and should be considered for octogenarians if appropriate.

Long-term survival after lobectomy in the elderly population is an important consideration. The calculated 5year overall survival of $52 \%$ in our series was comparable to previous reported 5-year overall survival of 18.2-69.6\% [7-17]. Furthermore, for stage IA patients the calculated 5year overall survival rate was excellent at $78 \%$ compared to $69.6 \%$ reported previously [9]. Univariate analysis in our 


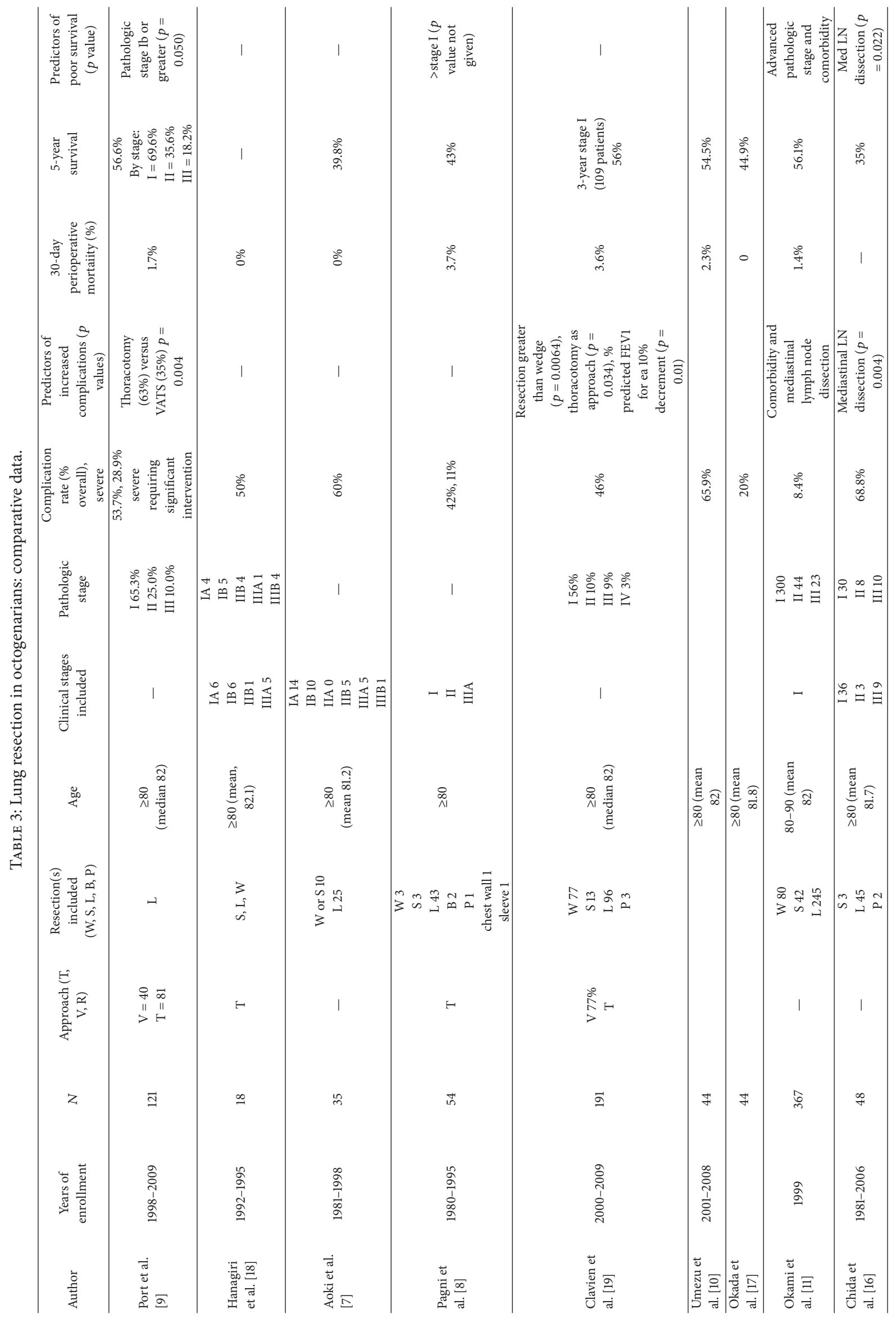




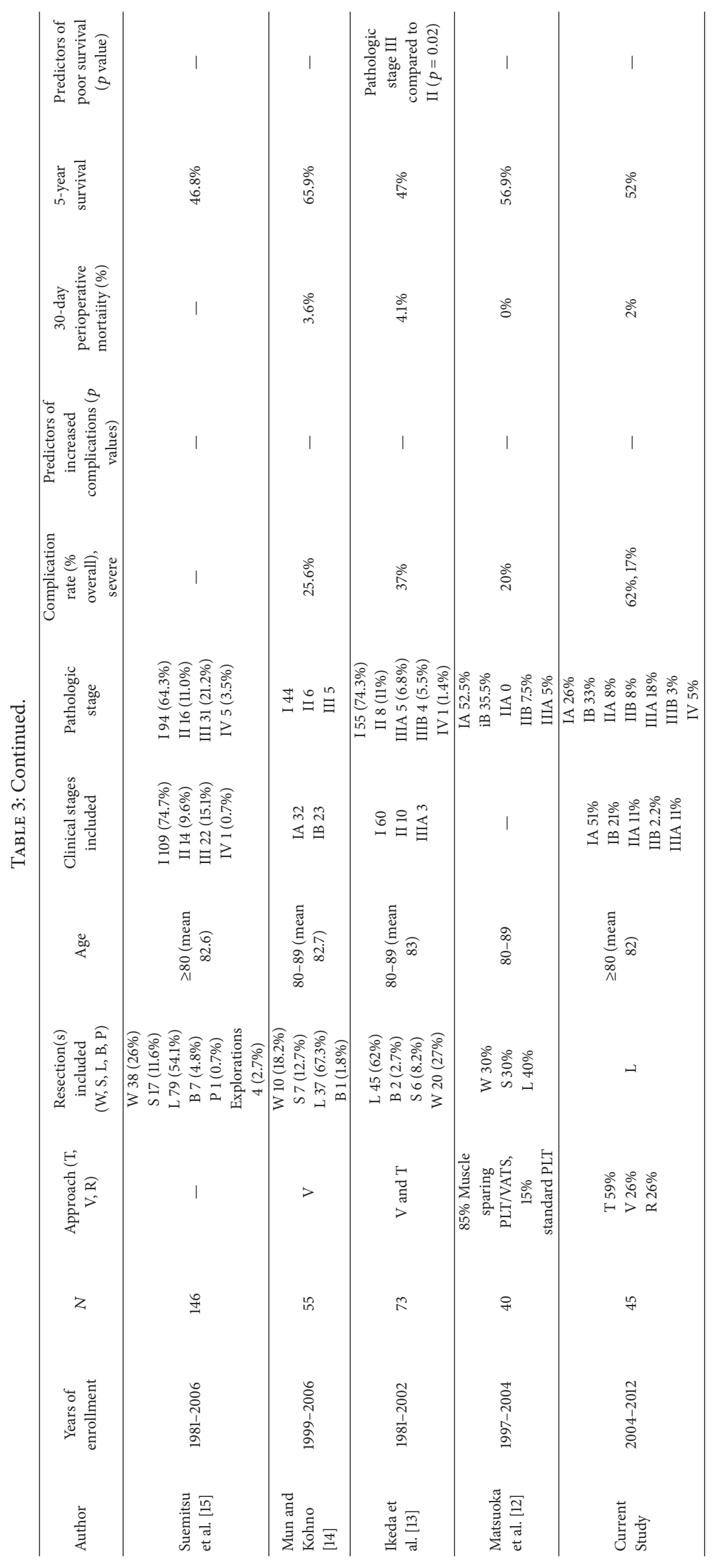




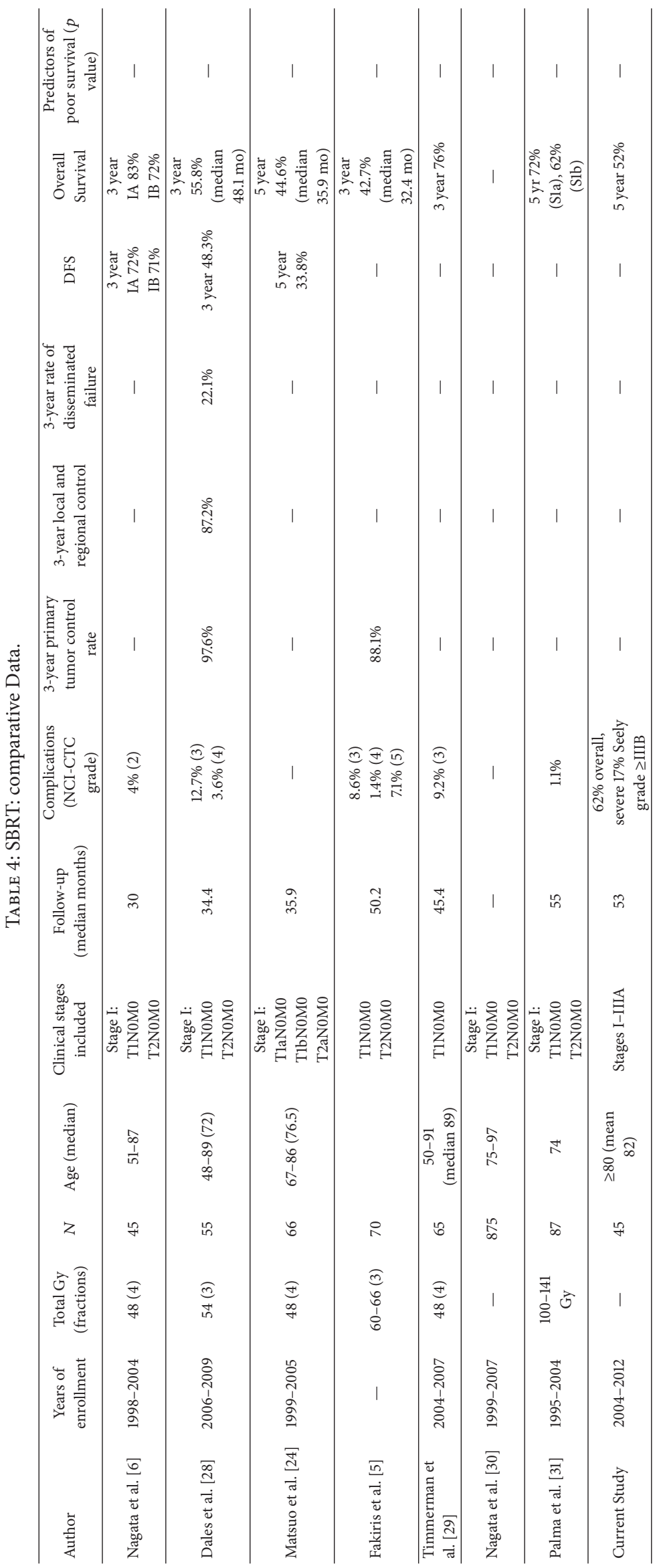


study failed to reveal predictors of better survival aside from lower pathologic stage. In this study, there was no statistically significant survival benefit dependent on operative approach.

We have observed that many of our patients are concerned with the possible need for a nursing facility (SNF) stay postoperatively. For patients in whom disposition data were available (36/45), 32 (88.9\%) were able to be discharged home with $4(11.1 \%)$ requiring discharge to a SNF. These rates are similar to other studies which report that 6\% [19] and 16.5\% [9] of octogenarians require SNF after lung resection.

Limitations to this retrospective review include patient selection bias, lack of a control group, small size, and variability of operative approach. The classification of complications as minor or major depending on level of intervention required does not reflect patient quality of life and the perceived invasiveness of the intervention. Additionally, these results may not be reproduced at other centers with different patient selection criteria and experience. Our follow-up was also limited at 1.7 years.

In today's society, where an 80 year old male can expect to live an additional 8 years (an 80-year-old female can live another 9.3 years) [27], carefully selected medically fit patients over 80 should be offered anatomic resection for early stage, operable NSCLC as per the NCCN guideline recommendations [3]. We found that employing an intervention-based, validated complication classification scheme is helpful when discussing expected surgical outcomes within this population (octogenarians) and across studies.

We have also shown that appropriately chosen octogenarians can undergo lobectomy with encouraging overall survival. These data should help physicians and surgeons understand the short-term risks and long-term survival associated with lobectomy, provide a framework for future comparison to SBRT or wedge resection, and allow surgeons to counsel older patients more thoroughly.

In conclusion, while $62 \%$ of octogenarians undergoing lobectomy had a complication, severe complications using the Seely morbidity and mortality complication schema occurred in only $15.6 \%$ of our study group. In addition, octogenarians deemed operable by a thoracic surgeon, regardless of stage or surgical approach, can achieve a reasonable 5-year survival of greater than $50 \%$. Using this data as a foundation, providers can accurately counsel similar patients regarding their surgical complication risk and expected survival.

\section{Disclosure}

This data was published as a preliminary abstract in the Journal of Thoracic Oncology, "Session PL03: Presidential Symposium including Top Rated Abstracts” Nov 2013; 8(11) S2-1348. The authors had full control of the production of this manuscript.

\section{Competing Interests}

The authors declare that there is no conflict of interests regarding the publication of this paper.

\section{References}

[1] T. K. Owonikoko, C. C. Ragin, C. P. Belani et al., "Lung cancer in elderly patients: an analysis of the surveillance, epidemiology, and end results database," Journal of Clinical Oncology, vol. 25, no. 35, pp. 5570-5577, 2007.

[2] N. N. A. Howlader, M. Krapcho, J. Garshell et al., Eds., SEER Cancer Statistics Review, 1975-2010, National Cancer Institute, Bethesda, Md, USA, 2013.

[3] Cancer NGfN-SCL, NCCN Guidelines Version 2.2012 NonSmall Cell Lung Cancer, 2012.

[4] S. M. Shirvani, J. Jiang, J. Y. Chang et al., "Comparative effectiveness of 5 treatment strategies for early-stage non-small cell lung cancer in the elderly," International Journal of Radiation Oncology Biology Physics, vol. 84, no. 5, pp. 1060-1070, 2012.

[5] A. J. Fakiris, R. C. McGarry, C. T. Yiannoutsos et al., "Stereotactic body radiation therapy for early-stage non-small-cell lung carcinoma: four-year results of a prospective phase II study," International Journal of Radiation Oncology Biology Physics, vol. 75, no. 3, pp. 677-682, 2009.

[6] Y. Nagata, K. Takayama, Y. Matsuo et al., "Clinical outcomes of a phase I/II study of 48 Gy of stereotactic body radiotherapy in 4 fractions for primary lung cancer using a stereotactic body frame," International Journal of Radiation Oncology Biology Physics, vol. 63, no. 5, pp. 1427-1431, 2005.

[7] T. Aoki, Y. Yamato, M. Tsuchida, T. Watanabe, J.-I. Hayashi, and T. Hirono, "Pulmonary complications after surgical treatment of lung cancer in octogenarians," European Journal of Cardiothoracic Surgery, vol. 18, no. 6, pp. 662-665, 2000.

[8] S. Pagni, J. A. Federico, and R. B. Ponn, "Pulmonary resection for lung cancer in octogenarians," Annals of Thoracic Surgery, vol. 63, no. 3, pp. 785-789, 1997.

[9] J. L. Port, F. M. Mirza, P. C. Lee, S. Paul, B. M. Stiles, and N. K. Altorki, "Lobectomy in octogenarians with non-small cell lung cancer: ramifications of increasing life expectancy and the benefits of minimally invasive surgery," Annals of Thoracic Surgery, vol. 92, no. 6, pp. 1951-1957, 2011.

[10] H. Umezu, S. Miyoshi, O. Araki et al., "Efficacy of functional operability algorithm for octogenarians with primary lung cancer," General Thoracic and Cardiovascular Surgery, vol. 60, no. 1, pp. 36-42, 2012.

[11] J. Okami, M. Higashiyama, H. Asamura et al., "Pulmonary resection in patients aged 80 years or over with clinical stage i non-small cell lung cancer: prognostic factors for overall survival and risk factors for postoperative complications," Journal of Thoracic Oncology, vol. 4, no. 10, pp. 1247-1253, 2009.

[12] H. Matsuoka, M. Okada, T. Sakamoto, and N. Tsubota, "Complications and outcomes after pulmonary resection for cancer in patients 80 to 89 years of age," European Journal of Cardiothoracic Surgery, vol. 28, no. 3, pp. 380-383, 2005.

[13] N. Ikeda, A. Hayashi, K. Iwasaki, N. Kajiwara, O. Uchida, and H. Kato, "Surgical strategy for non-small cell lung cancer in octogenarians," Respirology, vol. 12, no. 5, pp. 712-718, 2007.

[14] M. Mun and T. Kohno, "Video-assisted thoracic surgery for clinical stage i lung cancer in octogenarians," Annals of Thoracic Surgery, vol. 85, no. 2, pp. 406-411, 2008.

[15] R. Suemitsu, M. Yamaguchi, S. Takeo et al., "Favorable surgical results for patients with nonsmall cell lung cancer over 80 years old: a multicenter survey," Annals of Thoracic and Cardiovascular Surgery, vol. 14, no. 3, pp. 154-160, 2008.

[16] M. Chida, M. Minowa, Y. Karube et al., "Worsened long-term outcomes and postoperative complications in octogenarians 
with lung cancer following mediastinal lymph-node dissection," Interactive Cardiovascular and Thoracic Surgery, vol. 8, no. 1, pp. 89-92, 2009.

[17] A. Okada, T. Hirono, and T. Watanabe, "Safety and prognosis of limited surgery for octogenarians with non-small-cell lung cancer," General Thoracic and Cardiovascular Surgery, vol. 60, no. 2, pp. 97-103, 2012.

[18] T. Hanagiri, H. Muranaka, M. Hashimoto, A. Nagashima, and K. Yasumoto, "Results of surgical treatment of lung cancer in octogenarians," Lung Cancer, vol. 23, no. 2, pp. 129-133, 1999.

[19] P.-A. Clavien, J. R. Sanabria, and S. M. Strasberg, "Proposed classification of complications of surgery with examples of utility in cholecystectomy," Surgery, vol. 111, no. 5, pp. 518-526, 1992.

[20] A. J. E. Seely, J. Ivanovic, J. Threader et al., "Systematic classification of morbidity and mortality after thoracic surgery," Annals of Thoracic Surgery, vol. 90, no. 3, pp. 936-942, 2010.

[21] S. B. Edge and C. C. Compton, "The american joint committee on cancer: the 7th edition of the AJCC cancer staging manual and the future of TNM," Annals of Surgical Oncology, vol. 17, no. 6, pp. 1471-1474, 2010.

[22] T. J. Smith, L. Penberthy, C. E. Desch et al., "Differences in initial treatment patterns and outcomes of lung cancer in the elderly," Lung Cancer, vol. 13, no. 3, pp. 235-252, 1995.

[23] T. B. Lanni, I. S. Grills, L. L. Kestin, and J. M. Robertson, "Stereotactic radiotherapy reduces treatment cost while improving overall survival and local control over standard fractionated radiation therapy for medically inoperable non-small-cell lung cancer," American Journal of Clinical Oncology, vol. 34, no. 5, pp. 494-498, 2011.

[24] Y. Matsuo, K. Shibuya, Y. Nagata et al., "Preliminary report of late recurrences, at 5 years or more, after stereotactic body radiation therapy for non-small cell lung cancer," Journal of Thoracic Oncology, vol. 7, no. 2, pp. 453-456, 2012.

[25] U.S. Department of Health and Human Services, NIH/NCI, Common Terminology Criteria for Adverse events (CTCAE), Version 4.03.

[26] M. F. Berry, J. Hanna, B. C. Tong et al., "Risk factors for morbidity after lobectomy for lung cancer in elderly patients," The Annals of Thoracic Surgery, vol. 88, no. 4, pp. 1093-1099, 2009.

[27] M. F. Berry, M. W. Onaitis, B. C. Tong, D. H. Harpole, and T. A. D'Amico, "A model for morbidity after lung resection in octogenarians," European Journal of Cardio-thoracic Surgery, vol. 39, no. 6, pp. 989-994, 2011.

[28] R. E. Dales, G. Dionne, J. A. Leech, M. Lunau, and I. Schweitzer, "Preoperative prediction of pulmonary complications following thoracic surgery," Chest, vol. 104, no. 1, pp. 155-159, 1993.

[29] R. Timmerman, R. Paulus, J. Galvin et al., "Stereotactic body radiation therapy for inoperable early stage lung cancer," JAMA, vol. 303, no. 11, pp. 1070-1076, 2010.

[30] Y. Nagata, M. Hiraoka, and T. Shibata, "Stereotactic body radiation therapy for T1N0M0 non-small cell lung cancer: first report for inoperable population of a phase II trial by Japan Clinical Oncology Group (JCOG 0403)," International Journal of Radiation Oncology Biology Physics, vol. 84, no. 3, p. S46, 2012.

[31] D. Palma, O. Visser, F. J. Lagerwaard, J. Belderbos, B. J. Slotman, and S. Senan, "Impact of introducing stereotactic lung radiotherapy for elderly patients with stage I non-small-cell lung cancer: a population-based time-trend analysis," Journal of Clinical Oncology, vol. 28, no. 35, pp. 5153-5159, 2010. 


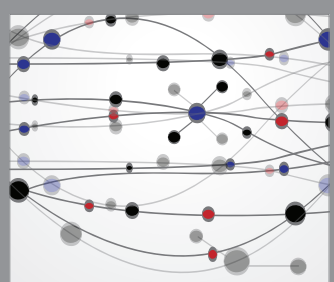

The Scientific World Journal
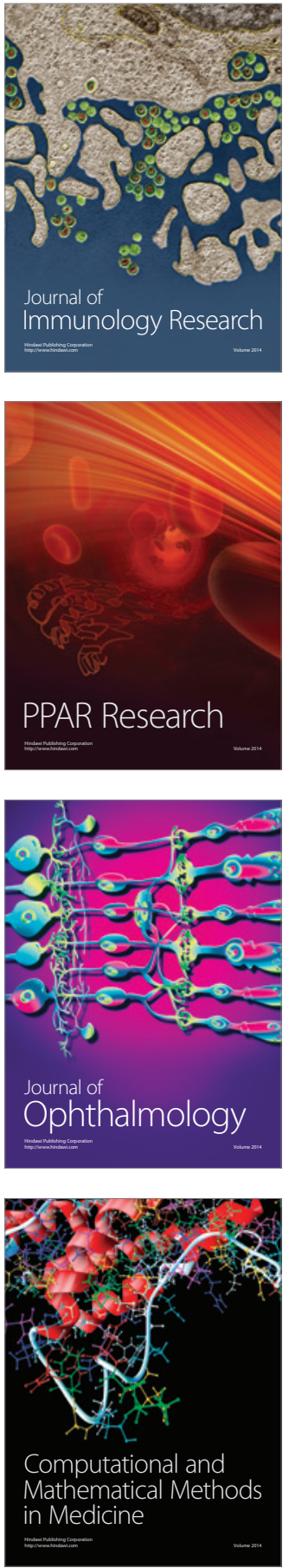

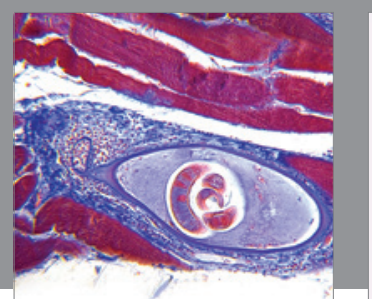

Gastroenterology Research and Practice
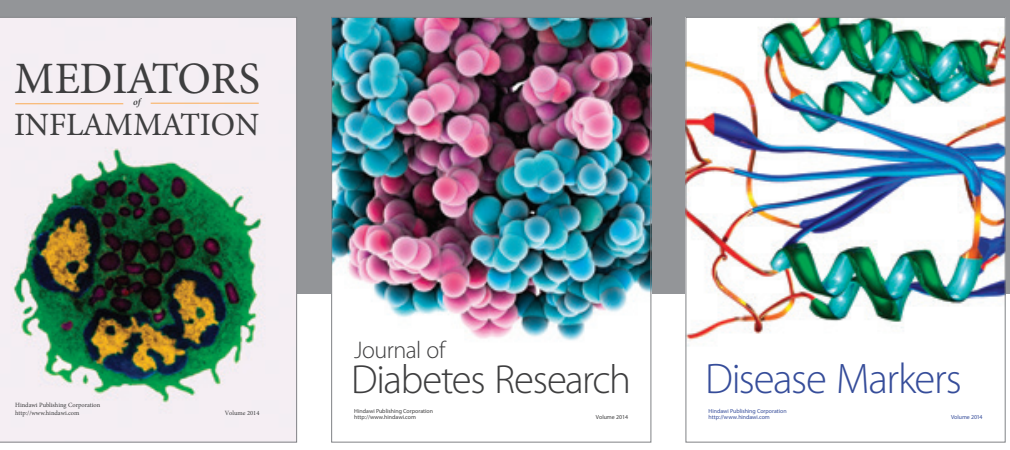

Disease Markers

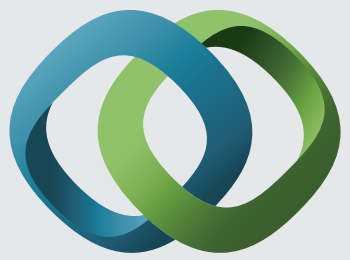

\section{Hindawi}

Submit your manuscripts at

https://www.hindawi.com
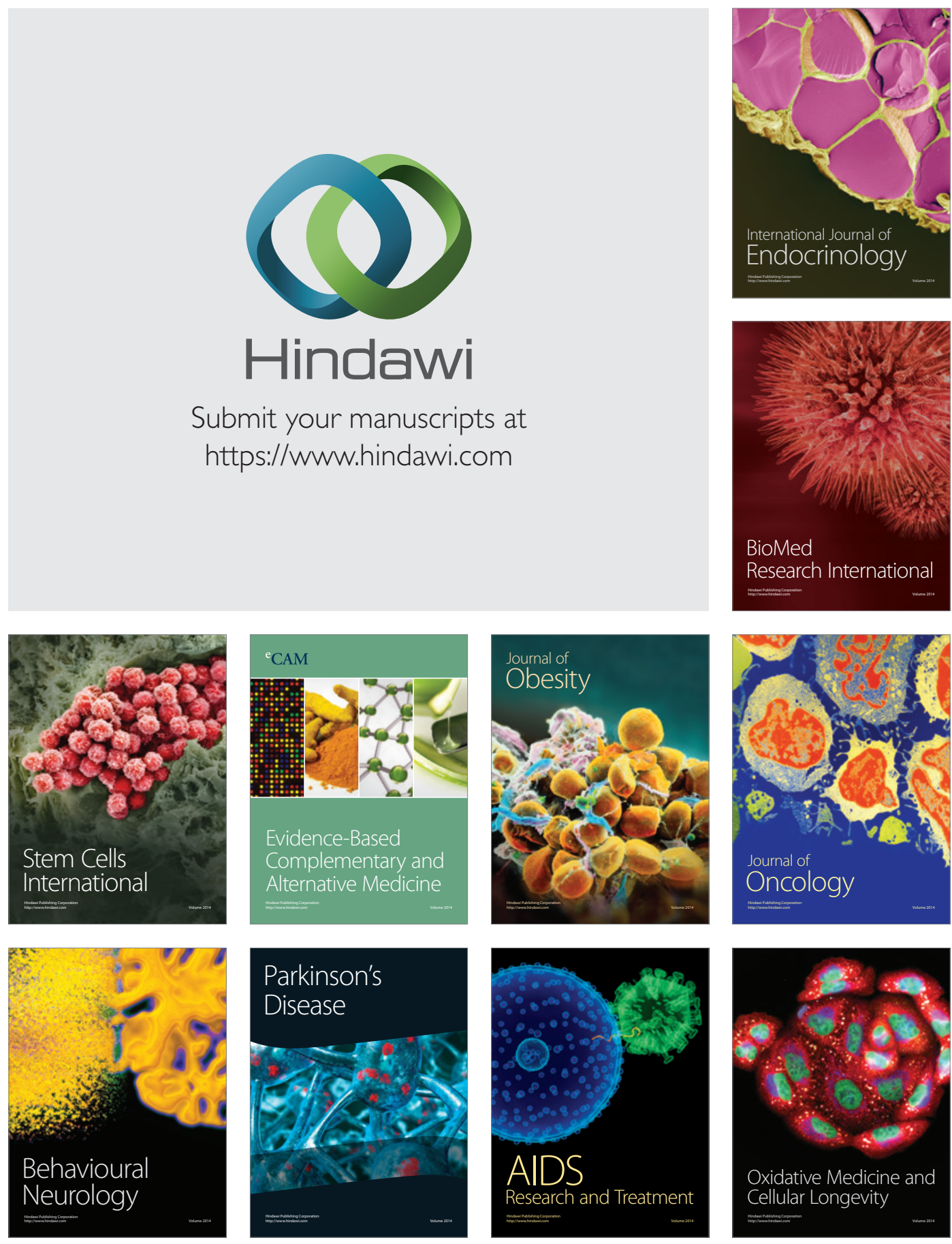